
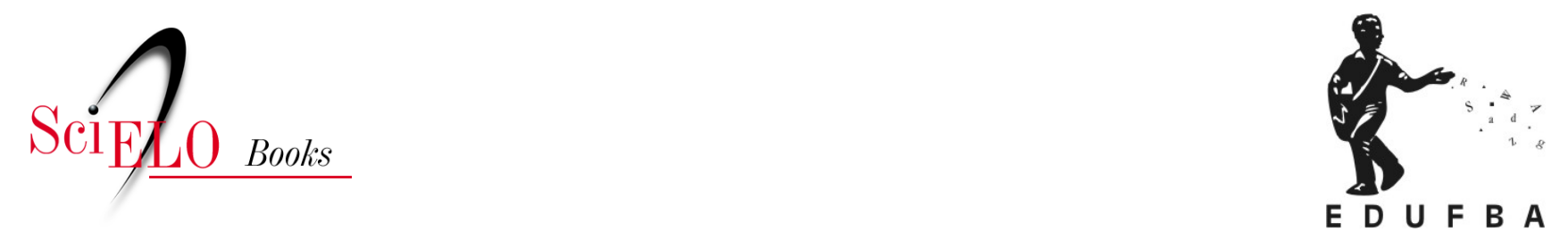

\title{
Panorama internacional dos sistemas de correios liberalização, regulação e reestruturação organizacional
}

\author{
Tadeu Gomes Teixeira
}

\section{SciELO Books / SciELO Livros / SciELO Libros}

TEIXEIRA, T.G. Panorama internacional dos sistemas de correios: liberalização, regulação e reestruturação organizacional. In: Os Correios e as políticas governamentais: mudanças e permanências [online]. Salvador: EDUFBA, 2016, pp. 19-35. ISBN: 978-85-232-2025-9. https://doi.org/10.7476/9788523220259.0003.

All the contents of this work, except where otherwise noted, is licensed under a Creative Commons Attribution 4.0 International license.

Todo o conteúdo deste trabalho, exceto quando houver ressalva, é publicado sob a licença Creative Commons Atribição $\underline{4.0}$. 


\section{Panorama internacional dos sistemas de correios: liberalização, regulação e reestruturação organizacional}

A partir da década de 1980, discussões e propostas para mudanças na estrutura de mercado, na forma de regulação e na modelagem organizacional dos operadores postais conduziram a radicais transformações no setor postal no cenário internacional.

Diante disso, neste capítulo são discutidas as transformações no sistema postal internacional com foco nos processos de reestruturação organizacional, nos mecanismos de regulação e nos processos de corporatização e privatização e suas principais consequências.

São apresentados também os principais argumentos acionados em prol das transformações e os seus aspectos ideológicos, bem como as consequências para os operadores postais públicos - transformação em empresas, modernizações em um cenário de liberalização dos mercados postais ou mesmo privatizações. Assim, analisam-se as principais tendências internacionais para compreender as diferenças e semelhanças com a transformação do setor postal brasileiro a partir da década de 1990.

\section{LIBERALIZAÇÃO, REGULAÇÃO, CORPORATIZAÇÃO, PRIVATIZAÇÃO: ETAPAS DA TRANSFORMAÇÃO}

Os sistemas de correios estiveram, de maneira geral, vinculados aos Estados nacionais. A regulação do setor postal baseou-se, até o final do século 
passado e nos mais diversos países, no monopólio de serviços e na exclusividade de um operador estatal. Desde as primeiras décadas do século XX, os departamentos ou órgãos de correios de propriedade estatal estruturaram-se em grandes corporações verticalizadas e integradas.

No entanto, com a ascensão e predomínio da ideologia neoliberal, governantes de diferentes países passaram a defender, a partir da década de 1980, transformações radicais na área. Naquela década, entretanto, os planos políticos para o setor foram apenas esboçados.

Os motivos alegados para as mudanças na regulação do setor postal e as diretrizes que deviam ser seguidas foram mais bem formulados e disseminados por agências multilaterais.

Em um relatório do Banco Mundial preparado com o auxílio da União Postal Universal (UPU) e publicado em 1996 - intitulado Redirecting Mail: Postal Sector Reform -, foram apresentadas as razões pelas quais as administrações postais deviam ser transformadas e quais os caminhos a seguir. Dentre elas, o Banco Mundial listou a suposta ineficiência e inadequação dos operadores públicos às necessidades de mercado e da população. Os correios estatais, na visão do Banco Mundial, não proporcionavam rentabilidade nem mesmo para investimentos na melhoria dos serviços, o que teria motivado diferentes governos a buscar reformas para o setor. (RANGANATHAN; DEY, 1996)

Nesse sentido, a Organização para Cooperação e Desenvolvimento Econômico argumenta que

[...] a contínua desregulamentação e liberalização dos outros setores da economia demonstraram os benefícios da competição na melhoria da qualidade, eficiência, inovação e redução dos preços aos consumidores, o que tem destacado a incongruência do monopólio e restrições para operação nesse setor. (OCDE, 1999, p. 21, tradução nossa)

Diante desses argumentos, verifica-se que as transformações no setor postal internacional precisam ser compreendidas a partir do vínculo que estabelecem com a hegemonia dos projetos neoliberais e seus receituários liberalizantes. ${ }^{1}$

1 O neoliberalismo, encampado por organismos multilaterais como o Banco Mundial e o Fundo Monetário Internacional (FMI), propunha um receituário que se tornou conhecido na América Latina como 
O avanço do desenvolvimento tecnológico também é relevante para se compreender as transformações no setor postal, seja como inovação nos meios de comunicação ou apenas argumento ideológico.

As transformações tecnológicas apareciam nos argumentos dos organismos multilaterais de forma ideológica e determinista. Segundo eles,

[...] o desenvolvimento tecnológico e em especial das telecomunicações (por meio do fax, telefone, e-mail, internet etc.) estão erodindo o 'coração do negócio' dos sistemas de correios tradicionais, com potencial para ameaçar sua capacidade em continuar financiando as obrigações sociais com os serviços universais. (OCDE, 1999, p. 21, tradução nossa)

Nessa mesma linha, o Banco Mundial já havia afirmado em 1996 que as tecnologias de informação eram responsáveis pela "necessidade" de liberalizar os mercados postais; tais argumentos, todavia, escondiam, por exemplo, o interesse de empresas de courier nos mercados nacionais e a pressão que exerciam pela liberalização postal. (RANGANATHAN; DEY, 1996)

Os projetos de reorganização do setor postal, assim, buscaram também atender aos interesses de operadores postais privados - empresas de courier -, pois, como argumentou a OCDE (1999), o crescimento das empresas no mercado postal aberto à competição tem sido limitado em razão dos correios estatais ainda terem "privilégios" nas operações.

$\mathrm{O}$ argumento ideológico é bem distinto do fenômeno sociológico associado à diminuição do fluxo de comunicação pessoal - cartas entre pessoas -, que representa um pequeno percentual no fluxo dos objetos postais. Ao mesmo tempo, o então diretor da União Postal Universal destacou que o mercado para transporte de mercadorias tem crescido muito com o processo de globalização. (LEAVEY, 1996)

\footnotetext{
"Consenso de Washington", cujas práticas deveriam desencadear uma liberalização dos mercados nacionais, processos de privatização, livre circulação de capitais financeiros e a reformulação das responsabilidades do Estado, que deveriam centrar-se na manutenção da livre competição e estabilização econômica, redução dos investimentos sociais e desoneração fiscal dos ricos, desregulamentação dos direitos trabalhistas etc., o que quase sempre desconsiderava a força de trabalho, a proteção social e os interesses públicos. (ANTUNES, 1999, 2002; CASTEL, 1999; CASTELLS, 2005) Para uma análise histórica do neoliberalismo e suas características, ver Anderson (1995).
} 
Isso significa, em suma, que as mudanças tecnológicas não afetaram o volume e o tráfego postal, embora tenha ocorrido uma mudança na natureza dos objetos postais, sobretudo com o incremento de postagens vinculadas às atividades comerciais. As transformações na tecnologia informacional, assim, podem ser situadas a partir de seu impacto no volume, fluxo e tipos de serviços prestados.

$\mathrm{Na}$ análise do Banco Mundial, havia a necessidade imediata de reforma postal, sobretudo nos países em desenvolvimento. E isso seria justificado porque o setor estaria ineficiente e insustentável, onerando os cofres públicos para cobrir déficits de operação. Para a agência, o setor sofria para manter as operações, que se tornavam cada vez mais obsoletas e ineficientes ao ponto de prejudicar o desenvolvimento de atividades econômicas que utilizavam a infraestrutura dos serviços postais. (RANGANATHAN; DEY, 1996) A alegada necessidade de reforma do setor postal deveria ser assumida e implantada como projeto de governo, segundo o Banco Mundial, sem deixar que "ideias tradicionais" limitassem os objetivos e esforços das reformas. (RANGANATHAN; DEY, 1996) Tais reformas, segundo a agência, deveriam compor um programa compreensível e integrado a ser seguido "imediatamente", sobretudo com a introdução de mecanismos de gestão alinhados à lógica de mercado.

As reformas deveriam ser acompanhadas por mudanças nos mecanismos de regulação do setor. Até 1996, a maioria dos países mantinha o monopólio postal ou algum tipo de reserva de mercado. Para essa agência, a liberalização do mercado era importante para garantir a atuação dos operadores privados sem restrições.

Com isso, o quadro que até então só contava praticamente com a presença de instituições governamentais no financiamento e gestão do setor postal seria alterado, o que supostamente garantiria mais eficiência e qualidade.

Com base nesse ideário, em 1999 os países membros da OCDE se reuniram para debater os rumos do setor. À mesa de discussões foi dado um sugestivo nome: Promoting Competition in Postal Services. O objetivo, como está explícito na denominação do fórum, foi debater e propor medidas para estimular e promover a competitividade nos serviços postais. Por competitividade entendia-se a abertura dos mercados nacionais com a quebra de 
monopólio dos operadores públicos e, de preferência, com a privatização das entidades estatais.

Segundo a OCDE, apesar de iniciativas de desregulamentação de diversos segmentos da economia, o mesmo não acontecera com o setor postal. Diante disso, o Banco Mundial chegou a afirmar que "enquanto significativos progressos em termos de reforma são feitos em outros setores do serviço público, o setor postal é um dos últimos bastiões da antiga ordem". (OCDE, 1999, p. 21, tradução nossa)

É relevante o fato de só em 1999 os países da OCDE terem se reunido para debater as transformações postais. $\mathrm{O}$ fato dos correios estatais terem passado incólumes pelos processos de privatização que ocorreram nos anos de 1980 e 1990, na Europa e Estados Unidos, já indica que o setor é "politicamente delicado", como afirmam Anderloni e Pilley (2002). O fato de o governo dos Estados Unidos, ainda em 2012, controlar o serviço postal e não o ter privatizado indica que não havia consenso sobre as mudanças para a organização do setor.

A OCDE (1999) apontou como necessário ao processo de reforma postal: a) eliminar o monopólio dos correios estatais; b) propiciar a abertura de mercado; e c) criar condições para que os serviços obrigatórios de correio fossem assegurados.

O monopólio postal tem sido justificado, segundo Anderloni e Pilley (2002), por prover as condições para sustentação de uma estrutura de custos capaz de satisfazer as necessidades de um mercado interno com preços abaixo dos praticados em mercados abertos. Na maioria dos países da OCDE (1999), as empresas estatais possuem o monopólio de certos segmentos do mercado postal. Esse monopólio é definido pelo preço ou peso de determinados serviços postais ou pela combinação de ambos. O objetivo do monopólio é subsidiar o custo dos serviços não comerciais prestados para entrega das correspondências em áreas de baixo retorno financeiro para as companhias.

Para a OCDE (1999), as restrições e monopólios devem ser eliminados porque gerariam uma suposta distorção no mercado ao favorecer o operador postal estatal. Segundo a organização, as áreas que precisassem de um atendimento especial seriam abrangidas por uma melhor alocação 
dos recursos pelos operadores privados. O mercado competitivo, alegam, encontraria a solução. $\mathrm{O}$ sistema postal precisa ser realizado em toda a extensão dos territórios nacionais e a custos razoáveis, o que nem sempre segue a lógica de mercado. As empresas postais privadas não funcionam com tal preocupação social, isto é, se a população de uma determinada região está sendo atendida de forma satisfatória a despeito do lucro.

Sendo assim, a lógica dos operadores privados (maximizar lucros) e a necessidade de atender à população não são convergentes, tornando-se um aspecto problemático para os defensores da liberalização. (ANDERLONI; PILLEY, 2002) Assim, os serviços não comerciais justificariam a manutenção da reserva de mercado. No entanto, onde a liberalização ganhou terreno cogita-se a criação de fundos com a contribuição dos operadores do mercado, públicos ou privados, para viabilizar as perdas decorrentes do atendimento às áreas não comerciais.

Juntamente com a liberalização do mercado, argumentam os representantes da OCDE, seria preciso eliminar barreiras à competitividade do setor postal, como as vantagens que os operadores estatais possuem, a exemplo das isenções fiscais.

As transformações nos sistemas de correios abarcavam, portanto, propostas para 1) liberalização postal e quebra de monopólios; 2) a criação de novas formas de regulação para o setor; e 3) a "corporatização" e privatização dos correios estatais.

Nesse sentido, o programa de reformas a ser implantado nos sistemas de correios deveria incluir crescentes reestruturações organizacionais, segundo o Banco Mundial, isto é, "reformas empresariais" capazes de melhorar a eficiência e melhorar os serviços. (RANGANATHAN; DEY, 1996) Assim, as "reformas empresariais" são adotadas para redirecionar as ações dos operadores postais à lógica de mercado, ou seja, consiste na adoção de princípios empresariais para gestão da organização postal.

Um passo adiante no processo é a corporatização (corporatization). O processo consiste na transformação de um órgão da administração pública direta - departamento, autarquia ou outro órgão de Estado - em uma corporação; a princípio, em uma empresa pública. Assim, trata-se de um processo que objetiva modificar os instrumentos legais para transformação jurídica dos 
correios estatais em empresas, desvinculando as entidades do poder público direto e garantindo autonomia gerencial e funcionamento com base no direito privado e empresarial mesmo quando o poder público continua a ser o proprietário ou acionista majoritário. Trata-se, portanto, de reformas organizacionais concatenadas à reestruturação dos modelos empresariais. (CASTELLS, 2005) Uma das faces, portanto, dos processos de reestruturação.

Ao observar e analisar os rumos das transformações postais nos países da OCDE, Anderloni e Pilley (2002) argumentam que as privatizações no setor têm seguido uma processualidade, o que é corroborado por Brandt (2007) ao estudar os países da União Europeia. Considerando que os operadores postais são inicialmente vinculados a ministérios ou departamentos de Estado, os passos no sentido da privatização têm sido transformá-los em empresas públicas com capital estatal; sociedades de economia mista com o Estado como sócio majoritário; sociedades de economia mista com ações preferenciais; sociedades anônimas majoritariamente de capital privado; e, finalmente, a privatização total. Todavia, algumas "medidas de privatização" são encontradas no setor mesmo antes da privatização completa das entidades, como a transferência da rede de atendimento a terceiros por meio de franquias ou outros mecanismos contratuais.

\section{O PROCESSO GRADUAL DE LIBERALIZAÇÃO POSTAL NA UNIÃO EUROPEIA}

Os serviços postais na União Europeia distribuem cerca de 135 bilhões de objetos postais por ano, com uma estimativa de lucro em torno de noventa bilhões de euros, o que equivale a $1 \%$ do produto interno bruto, conforme informações oficiais de 2013. (POSTAL..., 2013)

Os princípios básicos da União Europeia pressupõem a livre competição e a ausência de barreiras comerciais entre os países membros. Nesse sentido, enquanto nos demais setores a ideologia neoliberal atuou fortemente no processo de liberalização devido à convergência de objetivos - tornando-a uma opção política legitimada entre os agentes governamentais -, o setor postal europeu vem passando por uma liberalização impulsionada também pelos princípios e arranjos de integração regional. 
Segundo Anderloni e Pilley (2002) e Brandt (2007), os serviços postais na Europa eram prestados diretamente pelos Estados nacionais no início da década de 1980, juntamente com os serviços de telecomunicações.

De acordo com Horst (2005), as iniciativas no sentido de uma reforma postal na Europa remontam a 1988, quando os projetos para unificação do mercado postal foram apresentados com contornos mais bem delineados. A primeira iniciativa nesse sentido foi com a elaboração, em 1992, do Green Paper on Postal Liberalization. ${ }^{2}$ O documento, que convocou os Estados-membros a apresentarem as diretrizes para a reforma postal, iniciou o debate sobre as mudanças no setor. As contribuições dos países indicaram o caminho a seguir, adotado pelo Parlamento Europeu. Três resoluções foram aprovadas e adotadas a partir de então: a) o começo imediato da elaboração de propostas para liberalização e desenvolvimento do mercado único; b) a definição do entendimento acerca de "serviços universais" a serem prestados; e c) a elaboração de uma definição comum de "atividades que podem ser reservadas".

Segundo Anderloni e Pilley (2002), ficou acordado que essas definições seriam as mais restritas possíveis e, por outro lado, deveriam ser suficientes para suprir os serviços universais com um preço coerente com a natureza do serviço. Assim, buscou-se regulamentar os serviços no sentido de uma abertura postal ao mesmo tempo em que se estabeleciam as reduções dos serviços monopolizados.

Em 1997, depois de mais de três anos de discussões, aprovou-se a Primeira Diretiva Postal ${ }^{3}$ para os Estados-membros da União Europeia. Por essa Primeira Diretiva, procurou-se harmonizar a legislação e alcançar três principais objetivos, como afirmam Anderloni e Pilley (2002, p. 31): 1) garantir serviços universais com boa qualidade e acessível a todos os usuários, encorajando a abertura mais ampla possível da competição no setor; 2) estabelecer obrigações comuns para todos os prestadores de serviços universais; e

2 O Green Paper é um documento utilizado na União Europeia para suscitar debates em torno de um tema. Pode subsidiar, posteriormente, ações no Parlamento Europeu.

3 A Diretiva é um ato do Parlamento Europeu que obriga todos os Estados-membros a cumprir algumas determinações. Para isso, os Estados têm autonomia política e administrativa. No caso em questão, trata-se da Diretiva 97/67/CE. 
3) harmonizar as regras dos serviços universais, as condições de acesso e as regras de qualidade.

De acordo com Horst (2005), ao estabelecer como objetivo a abertura de mercado impôs-se aos países-membros o limite aos serviços monopolizados. Assim, tanto para os serviços nacionais como transnacionais, os objetos postais monopolizados deveriam ter no máximo trezentos e cinquenta gramas ou cinco vezes a tarifa básica. Além disso, buscou-se criar órgãos reguladores nacionais.

Com a Primeira Diretiva Postal de 1997 apontou-se a estrutura e os rumos que Estados- membros deveriam adotar. No quadro 1, a seguir, verificam-se as principais deliberações:

QUADRO 1 - SÍNTESE DAS DECISÕES ACERCA DO SERVIÇO POSTAL EUROPEU COM A PRIMEIRA DIRETIVA POSTAL (1997)

\begin{tabular}{|l|l|l|}
\hline \multicolumn{2}{|l|}{ Elementos Obrigatórios } & Elementos Opcionais \\
\hline Núcleo Institucional & Ambiente Institucional & Ferramentas Disponíveis \\
\hline - Serviços Universais; & - Tarifas baseadas nos custos; & - Autorizações e licenciamentos; \\
- Padrão de qualidade para & - Sistema contábil transparente; & • Fundos de compensação. \\
$\begin{array}{l}\text { serviços internacionais; } \\
\text { - Limite à área reservada } \\
\text { (monopolizada). }\end{array}$ & - Separação do órgão & \\
& - Padrões de qualidade para & \\
& serviços nacionais. & \\
\hline
\end{tabular}

Fonte: Adaptado de Toledano, (apud ANDERLONI; PILLEY, 2002, p. 31, tradução nossa).

Verifica-se que as diretrizes acordadas foram para garantir um serviço postal universal, o estabelecimento de padrões de qualidade dos serviços internacionais baseado em prazos de entrega e a eliminação gradual do monopólio. Simultaneamente, os operadores postais deviam estabelecer princípios de gestão condizentes com a transparência atribuída a certos arranjos organizacionais e atuar em um ambiente onde fosse instituído um órgão regulador desvinculado do correio estatal.

Os aspectos discutidos e regulamentados na Primeira Diretiva foram ampliados na "segunda onda" de abertura do mercado postal em 2002, quando foi aprovada a Segunda Diretiva Postal. ${ }^{4}$ HORST, 2005) Essa Segunda Diretiva foi motivada por pressão de grupos empresariais e políticos que se fundamentaram em supostas melhorias na qualidade do mercado

4 Trata-se da Diretiva 2002/39/CE 
aberto à competição, que estaria mais eficiente, inovador e com melhor qualidade. Para tais grupos, essas melhorias teriam sido possíveis pela adoção de novas tecnologias e por segmentações de mercado que só a competitividade foi capaz de proporcionar. (ANDERLONI; PILLEY, 2002)

Com a adoção da Segunda Diretiva, foi reduzido o monopólio dos correios estatais para objetos postais domésticos com até cem gramas ou três vezes a tarifa básica, a partir de 2003; em 2006, esses valores seriam alterados para cinquenta gramas, ou duas vezes e meia a tarifa básica.

A Segunda Diretiva Postal, segundo Horst (2005), também estabeleceu prazos para a liberalização total, embora tenha deixado a possibilidade de dilatar os prazos para alguns países (Grécia, Portugal, Espanha, Itália, França etc.), caso provassem necessidade em estender o monopólio. Em 2004, com a entrada de dez novos membros na União Europeia e a consequente necessidade de adaptarem suas legislações - incluindo a postal -, estabeleceu-se que até 2006 poderiam usufruir do monopólio dos objetos postais com até trezentos e cinquenta gramas ou três vezes a tarifa básica.

A Segunda Diretiva também estabeleceu um "passo decisivo" para análise e revisão dos processos de liberalização e redução/eliminação dos monopólios, bem como uma análise da qualidade dos serviços prestados. Essa revisão foi marcada para 2006, e o prazo para abertura total dos mercados estabelecido para 2009. Todavia, em decorrência da impossibilidade de cumprimento dos prazos, a abertura total foi remarcada pelo Parlamento Europeu para ocorrer até 2011, e para os países-membros que ingressaram tardiamente na comunidade foi estendido o prazo até 2013 para adequarem-se às Diretivas (caso, principalmente, dos países do Leste Europeu).

Para evitar distorções nos mercados, os Estados-membros que tivessem liberalizado seu mercado poderiam recusar as empresas dos países que ainda operavam sob monopólio em seus territórios.

Para os serviços universais, estabeleceu-se que todos os cidadãos da comunidade de países têm direito à distribuição domiciliária pelo menos uma vez por semana e recolhimento de objetos postais cinco dias por semana. (ABERTURA..., 2008) Tendo por base essas diretrizes, portanto, o 
mercado postal da União Europeia tornou-se aberto em 2011, sendo 2013 o ano limite para os países do Leste Europeu.

Verifica-se a partir do caso específico da União Europeia, formada também por muitos países da OCDE, que a lógica da integração regional contribui com a liberalização postal, mas apenas acelerando o processo, já que foram as diretrizes vinculadas ao ideário neoliberal que orientaram o processo. Dessa maneira, a "onda de liberalização" postal que se abateu sobre a Europa resulta não somente da integração regional, mas também de escolhas políticas vinculadas à ideologia neoliberal.

\section{TRANSFORMAÇÕES NOS SISTEMAS DE CORREIOS}

A liberalização gradual dos mercados postais na União Europeia concatena-se aos processos de privatização. Nesse sentido, a regulação do setor foi pensada e formatada para propiciar a entrada e permanência de operadores privados no mercado. Contudo, as opções de cada país mostram que o processo se diferencia conforme as opções dos dirigentes políticos.

Nessa direção, Brandt (2007) mostra que no âmbito da União Europeia alguns países optaram por trilhar um caminho próprio. Nesse sentido, os trezentos e cinquenta anos do correio sueco como órgão da administração pública findaram-se em 1994, quando foi transformado em sociedade anônima e renomeado Posten $A B$. O objetivo foi retirar todo e qualquer auxílio estatal à empresa, que deveria competir abertamente no mercado. Em 2002 o banco postal foi separado da empresa postal, passando a ser uma empresa à parte.

Na Holanda, em 1989, o correio foi transformado em empresa pública (a KPN) e, em 1994, em sociedade anônima. Em 1996, a KPN adquiriu a empresa australiana TNT. Em 1998, houve a divisão entre correios e telecomunicações - a PTT correios e a KPN Telecom. Em 2002, por ambições internacionais, tornam-se subsidiárias da TNT Post Group (TPG).Em 2006, a companhia passa a ser TNT Post, que se subdivide em 2011, novamente, em duas: PostNL (correios) e TNT Express. (ABVAKABO..., 2011)

Os serviços postais na Áustria, que até o início da integração do mercado postal eram monopolizados pelo Estado, passaram, a partir de 1988, a 
ser alvo de propostas de liberalização. Antes disso, no entanto, houve um processo de corporatização do correio estatal, que deixou de ser um departamento da Administração Direta, a Administração Postal e Telegráfica, para ser transformado em empresa pública: Post und Telekom AG (PTA).

Em 1999 houve a separação dos serviços postais do setor de telecomunicações, o que originou duas empresas distintas. Até 2006, a Post AG ainda era do Estado austríaco, mesmo com a abertura do capital da empresa. Naquele ano, no entanto, o governo austríaco vendeu na bolsa de valores $49 \%$ das ações, permanecendo com $51 \%$ restantes e, por conseguinte, com o controle acionário. A partir disso, a empresa foi transformada em três, cada qual com atuação em setores distintos: cartas, encomendas e logística e rede de atendimento (agências, serviços financeiros e comercialização).

Dessa maneira, os serviços postais na Áustria passaram por uma transformação: de um mercado sem competição, transformou-se em um mercado múltiplo e com uma pequena área reservada até 2007, quando $75 \%$ do mercado foram abertos à competição. Com isso, o operador estatal - Post AG - possuía 98\% do mercado. Apesar disso, empresas transnacionais, como a United Parcel Service (UPS), TNT, Deutscher Paket Dienst (DPD) e Federal Express (FEDEX) estão ativas no mercado de encomendas e serviços expressos. Com isso, apesar da Post AG liderar o setor postal, empresas transnacionais privadas já atuavam visivelmente no mercado austríaco. (BRANDT, 2007)

O processo de liberalização na Alemanha começou na década de 1980, e já em 1984 as autoridades alemãs abriram o mercado à competição em alguns segmentos. De acordo com Brandt (2007), em 1989 o Federal Service Postal (Deutsche Bundespost) foi dividido em três companhias estatais: serviços postais (Postdienst), serviços financeiros (Postbank) e serviços de telecomunicações (Telekom). As três companhias tornaram-se legalmente empresas públicas da Administração Federal e independentes para decisões cotidianas, mas diretamente controladas pelo ministro dos Correios e Telecomunicações.

Desde 1994 foram feitos esforços para privatizar essas empresas, e a partir de 1995 foram transformadas em sociedades de economia mista. Em um primeiro momento, o governo alemão ficou com todas as ações. Com essas mudanças, o serviço postal foi batizado de Deutsche Post AG (DPAG), que desde 1998 vinha comprando outras empresas. 
O passo decisivo rumo à liberalização postal na Alemanha, contudo, resultou da Primeira Diretiva Postal - acompanhando os passos da União Europeia. Em 1998 esse país iniciou a formulação da abertura gradual do mercado em conjunto com as diretrizes europeias. Assim, estabeleceu a abertura gradual do mercado até 2007, quando a Alemanha abriu totalmente o mercado.

Antes disso, a partir de 2000 iniciou o processo de corporatização da DPAG - a empresa estatal - com a oferta pública de ações. Nesse ínterim, a empresa foi renomeada para Deutsche Post World Net $(D P W N)$ - empresa holding, com a DPAG como única acionista.

Em 2005, no entanto, investidores privados tornaram-se sócios majoritários da Deutsche Post World Net, comercialmente denominada de Deustsche Post DHL, transnacional líder do mercado global de logística e encomendas expressas. (BRANDT, 2007) No mercado alemão, somente empresas postais com predominância de capital privado estão presentes. Em 2006, sete empresas dominavam o mercado, formando um oligopólio. De forma direta, portanto, a liberalização postal na Alemanha foi conduzida concomitantemente a uma privatização do correio público. (BRANDT, 2007)

Na Bélgica, até o início da liberalização postal europeia, também havia poucos competidores no mercado nacional. A abertura comercial do setor naquele país seguiu o cronograma proposto pela União Europeia. Até então, o De Post possuía o monopólio postal e havia sido organizado como empresa pública já em 1991. Desde 2005, no entanto, a participação de acionistas foi autorizada com duas restrições: a participação do Estado belga devia ser sempre superior a 50\% das ações e estas devem garantir o direito a mais de $75 \%$ dos votos em todas as subsidiárias da empresa.

Apesar disso, desde que a abertura do mercado se iniciou, o número de empresas privadas tem aumentado na Bélgica. Empresas subsidiárias da Deuschte Post Welt Net e TPG Post estão em nichos específicos, sobretudo em segmentos transnacionais de revistas e jornais, de acordo com Brandt (2007). Há, no entanto, maior competição nos segmentos de encomendas e serviços expressos. Cinco empresas possuem $62 \%$ do mercado, sendo o restante compartilhado por empresas menores. As cinco maiores empresas são as transnacionais DHL, Fedex, TNT e UPS, além da belga Belgium railway-subsidiary $A B X$. Além dessas maiores, há um enorme número 
de empresas menores. Ao todo, quase mil empresas atuam no mercado postal belga. (BRANDT, 2007)

No Reino Unido, a principal mudança organizacional desde 1990 envolveu a transformação das companhias postais em sociedades anônimas em 2001, sendo o conglomerado denominado, a partir de 2002, de Royal Mail Group. São três operadores postais públicos: Royal Mail (cartas e pequenas encomendas), Parcelforce (encomendas maiores) e Post Office Counters (agências de correios), subsidiárias da estatal Royal Mail Holdings.

Apesar da opção por liberalizar vagarosamente o mercado postal, a partir de 2006 o Reino Unido abriu completamente o setor à competição. Apesar da predominância dos correios estatais, havia muitas pequenas empresas que prestavam serviços locais, embora empresas maiores como TNT e DHL também estivessem com boa fatia do mercado de encomendas expressas. As agências de atendimento eram, em sua maioria, franqueadas e, portanto, privadas. Eram mais de dezesseis mil agências onde se realizavam os mais diversos tipos de serviços. No caso do Reino Unido, a abertura comercial não levou à privatização do operador estatal, mas conduziu ao aumento do número de empresas que competem no mercado de cartas.

Os serviços postais, mesmo depois do início do processo de liberalização no âmbito da comunidade europeia, eram prestados, até meados de 2007, predominantemente, por correios públicos. A maior participação do operador público pode ser encontrada na Polônia, com 99\% do mercado, enquanto a menor participação do operador público está na Suécia, com 93\% do mercado compartilhado e onde a liberalização total do mercado ocorreu em 1992. Constata-se, como aponta Brandt (2007), que a Alemanha foi o único país a transferir totalmente aos empresários o setor postal.

Esses casos nos mostram, assim, que o primeiro passo rumo às privatizações no continente europeu tem sido a constituição de empresas postais autônomas vinculadas aos Estados e que seguem a lógica público-privada. Ou seja, são criadas empresas públicas com autonomia gerencial, apesar de não estarem sob uma racionalidade concatenada à livre competição e gozarem de benefícios fiscais e reserva de mercado.

Dessa maneira, o processo gradual de corporatização tem reformulado os modelos empresariais. De maneira geral, segundo Anderloni e Pilley 
(2002, p. 18), os modelos organizacionais utilizados nas reestruturações organizacionais podem dividir o correio estatal em diversas companhias, formando holdings, por exemplo, ou empresas com atuação em segmentos específicos do mercado.

Assim, há um processo concomitante de transformação dos operadores estatais de correios em empresas públicas e, em seguida, a cisão delas em outras empresas ou integrantes de holdings que frequentemente incorporam serviços bancários, seguradoras e telecomunicações.

Da mesma forma, isso também vem ocorrendo fora da União Europeia, como é o caso, por exemplo, do Japão. Em 2003, os serviços postais japoneses passaram a ser prestados por uma empresa estatal e pouco depois ela foi privatizada, sendo dividida em quatro empresas que passaram a integrar uma holding. $\mathrm{O}$ mesmo ocorreu anteriormente na Nova Zelândia, quando, em 1987, a New Zealand Post \& Telecommunications se dividiu em três empresas: Correios da Nova Zelândia, Banco Postal e Telecom, sendo as duas últimas privatizadas; já a liberalização postal ocorreu em 1998 com a quebra do monopólio. (ANDERLONI; BRANDT, 2007; PILLEY, 2002)

QUADRO 2 - REESTRUTURAÇÃO DOS MODELOS EMPRESARIAIS E CORPORATIZAÇÃO EM PAÍSES DA OCDE

\begin{tabular}{|l|l|l|}
\hline País & $\begin{array}{l}\text { Ano em que deixou de ser } \\
\text { departamento de Estado }\end{array}$ & $\begin{array}{l}\text { Sentido da reestruturação } \\
\text { organizacional e corporatização }\end{array}$ \\
\hline Japão & 2003 & $\begin{array}{l}\text { Empresa estatal > Privatização > Divisão } \\
\text { em quatro empresas de uma holding. }\end{array}$ \\
\hline Nova Zelândia & 1987 & $\begin{array}{l}\text { Divisão da New Zealand Post \& Telecommunications } \\
\text { em três empresas: Correios da Nova Zelândia, } \\
\text { Banco Postal e Telecom, sendo as duas } \\
\text { últimas posteriormente privatizadas. }\end{array}$ \\
\hline Suécia & 1994 & $\begin{array}{l}\text { Transformado em sociedade anônima. Em 2002, } \\
\text { a Posten AB separou-se do Banco Postal. }\end{array}$ \\
\hline Holanda & 1989 & $\begin{array}{l}\text { Empresa pública (1989) > Sociedade de } \\
\text { economia mista (1994) > Separação dos } \\
\text { correios e telecomunicações (1998) > Torna- } \\
\text { se subsidiária de multinacional (2002). }\end{array}$ \\
\hline Alemanha & 1989 & $\begin{array}{l}\text { Dividido em três empresas públicas: correios, } \\
\text { telecomunicações e banco postal > Sociedades } \\
\text { de economia mista (1995) > Início da privatização } \\
\text { em 2000 por meio de oferta de ações; torna- } \\
\text { se DPWN/DHL > Em 2005, acionistas privados } \\
\text { tornam-se majoritários da empresa líder do mercado } \\
\text { global de logística e encomendas expressas. }\end{array}$ \\
\hline
\end{tabular}

Fonte: Elaboração pelo autor. 
O segundo passo no processo de corporatização tem sido a adoção de formas jurídicas privadas associadas à abertura de capital das empresas e a consequente transformação das empresas em sociedades anônimas. O terceiro e último passo, nesse processo, é a privatização das empresas públicas de economia mista. (ANDERLONI; PILLEY, 2002)

\section{CONSIDERAÇÕES FINAIS}

O mapeamento das transformações no setor postal internacional revela um cenário de mudanças radicais. Os fatores que têm motivado tais transformações são vários, mas destacam-se, concordando com Leavey (1996, p. 15), os seguintes: 1) a emergência de grupos privados no setor de transportes e comunicações; 2) o lobby de grupos de operadores postais privados (courier), que pressionam para que os segmentos monopolizados sejam reduzidos ao máximo;3) as orientações de agências e instituições como Banco Mundial e Fundo Monetário Internacional, que exigiam programas de "ajustes estruturais" dos países para dar maior espaço ao capital privado e menor intervenção estatal; e 4) os mecanismos de integração dos mercados regionais na União Europeia.

As transformações, em um primeiro momento, transferem de uma lógica pública para a privada os sistemas de correios, quase sempre assumindo a forma de empresas públicas. Isso tem sido um dos primeiros passos no processo gradual de privatização, pois possibilita a introdução de novas formas de administração concomitantemente à preparação da abertura de mercado e possível privatização do correio estatal. Trata-se, em suma, de um processo de corporatização que precede processos de privatização.

O que se observa, portanto, é um continuum entre a proposta das agências multilaterais para "modernizar" o setor postal mundial e as mudanças efetivas, sobretudo em relação aos processos de liberalização concomitantes às reformas organizacionais dos correios tradicionais (estatais). Esses processos, de uma maneira geral, têm resultado em privatizações ou, pelo menos, na venda de ações das empresas postais.

Assim, pode-se concluir que a liberalização postal associa-se às privatizações e à abertura do capital das empresas estatais sob a justificativa da modernização gerencial. 
As mudanças têm provocado processos graduais de concentração de mercado, isto é, há uma tendência à formação de oligopólios no mercado postal, sobretudo entre grupos postais transnacionais. A formação de oligopólios, em tese, deveria ser evitada pela regulação do mercado, que tem deixado de ser uma responsabilidade estatal para ser realizada por órgãos reguladores independentes.

A criação de agências reguladoras, recomendação de organismos multilaterais como Banco Mundial e OCDE, tem sido realizada para organizar e estabelecer as condições de operação em mercados postais abertos. Caberia às agências reguladoras garantir uma uniformidade e igualdade no tratamento às empresas no mercado competitivo e na prestação de serviços universais obrigatórios. A regulação do mercado postal aberto teve, em linhas gerais, como premissa a competitividade entre operadores, a qualidade dos serviços prestados, os valores das tarifas e as normas trabalhistas.

De acordo com Brandt (2007), a regulação postal no contexto da União Europeia tem sido realizada por meio de diferentes instrumentos, dentre os quais o próprio poder público, por regras, normas e padrões para prestação dos serviços, por contratos e por agências reguladoras autônomas. Ao aprovar Diretivas para liberalização do setor, ficou garantida a autonomia para cada Estado-membro decidir entre agências reguladoras ou pelos próprios ministérios estatais.

A regulação do mercado postal tem sido realizada de diferentes maneiras no contexto europeu, com variados desempenhos dos órgãos reguladores. (BRANDT, 2007) No entanto, a regulação estatal tem sido mais eficiente do que as agências autônomas, porque a capacidade de atuação destas é limitada. De forma paradoxal, apenas no mercado postal da Alemanha - que foi um dos primeiros a liberalizar o mercado - as condições de trabalho são elementos examinados pelas agências reguladoras ao concederem ou renovarem o licenciamento das empresas postais.

O sistema postal brasileiro, contudo, possuía uma empresa desde 1969. Quais eram as suas características? Quais as semelhanças e diferenças com esse cenário internacional? Por outro lado, como as tendências internacionais influenciaram as estratégias para o setor postal brasileiro a partir da década de 1990? É o que se analisa nos próximos capítulos. 